\title{
Repair versus replacement of mitral valves in cases of severe rheumatic mitral stenosis: mid-term clinical outcomes
}

\author{
Yuqing Jiao, Tiange Luo, Haibo Zhang, Jie Han, Yan Li, Yixin Jia, Shuai Zheng, Xu Meng \\ Cardiac Valve Center, Department of Cardiac Surgery, Beijing Anzhen Hospital, Capital Medical University, Beijing 100029, China \\ Contributions: (I) Conception and design: Y Jiao, T Luo, X Meng; (II) Administrative support: X Meng; (III) Provision of study materials or patients: \\ T Luo, H Zhang, J Han, Y Li, Y Jia, S Zheng; (IV) Collection and assembly of data: Y Jiao, T Luo; (V) Data analysis and interpretation: Y Jiao, T \\ Luo; (VI) Manuscript writing: All authors; (VII) Final approval of manuscript: All authors. \\ Correspondence to: Xu Meng, Masters. Cardiac Valve Center, Department of Cardiac Surgery, Beijing Anzhen Hospital, Capital Medical University, \\ Beijing 100029, China. Email: sky3ab@163.com.
}

\begin{abstract}
Background: We compared and analyzed differences between repair vs. replacement of mitral valves on severe rheumatic mitral stenosis by looking at mid-term clinical outcomes.

Methods: Patients with severe rheumatic mitral stenosis (mitral valve area $\leq 1.5 \mathrm{~cm}^{2}$, with or without mitral valve regurgitation) from January 2011 to September 2017 were divided into two groups: a mitral valve repair group (MVP) and a mitral valve replacement group (MVR). After propensity score matching between the two groups, we compared changes in post-operation clinical outcomes. We also monitored changes in left ventricular longitudinal and circumferential strain in successfully matched patients (20 pairs) by echocardiography speckle tracing.

Results: A total of 921 patients were recruited (221 in MVP and 700 in MVR). After a propensity score matching, 216 cases were selected with 108 patients in each group. With a follow-up period of 3 months to 7.1 years, the incidence of heart failure was observed to be significantly higher in the MVR group than in the MVP group $(\mathrm{P}<0.05)$. Echocardiographic speckle tracking imaging analysis showed that left ventricular longitudinal strain decreased in the MVR group, suggesting that a change of cardiac structure may affect the cardiac function.

Conclusions: Selecting suitable patients for mitral valve repair is feasible even for patients with severe rheumatic mitral stenosis. In our study, compared with prosthetic valve replacement in these patients, valve repair still significantly reduced the valve-related complications rates and improved the quality of life during the follow-up.
\end{abstract}

Keywords: Rheumatic; mitral stenosis; mitral valve repair; mitral valve replacement; follow-up studies

Submitted Mar 14, 2019. Accepted for publication Aug 06, 2019.

doi: $10.21037 /$ jtd.2019.08.101

View this article at: http://dx.doi.org/10.21037/jtd.2019.08.101

\section{Introduction}

China has a large population of patients with rheumatic mitral valve disease $(1,2)$. The primary treatment for these patients is mitral valve replacement surgery, and using a mitral valve repair procedure is extremely low in number. The pathological changes of rheumatic mitral valve lesions include leaflet thickening and fibrosis, commissural, and subvalvar fusion, followed by slow calcific degeneration (3-5).
Given the diversity and complexity of the pathological changes of the rheumatic mitral valve, rheumatic mitral valve repair has always been a challenge. A standard view has been that mitral valve repair has fewer complications than mitral valve replacement, and therefore is more beneficial in terms of quality of life to patients with degenerative mitral valve disease (6-8). However, in patients with rheumatic mitral valve diseases, this view is controversial (9). Studies 
show that if appropriately selected, and some cases can also achieve good results with mitral valve repair $(10,11)$.

Our center is one of the early pioneers of rheumatic mitral valve repair research in China (more than 10 years). We have developed our own surgical procedures and treatments. For instance, since 2012, Dr. Meng has realized the importance of evaluating lesions of the mitral valve from leaflet, commissure, and sub-valve apparatus with the naked eyes in operation. We used this as a criterion for case selection and surgical approach $(12,13)$, which effectively improved the maneuverability and success rate of rheumatic mitral valve repair.

To further objectively evaluate clinical differences between mitral valve replacement $v$ s. mitral valve repair, we conducted a retrospective study on patients with severe rheumatic mitral stenosis who underwent surgery in our center in the past 7 years.

\section{Methods}

\section{Patients selection and comparison of clinical parameters}

From January 2011 to September 2017, patients with severe rheumatic mitral valve stenosis [mitral valve area $\leq 1.5 \mathrm{~cm}^{2}$ (6), with or without mitral valve regurgitation] for mitral valve surgery in our center were selected. Except for valve surgery and radio-frequency ablation, we excluded patients who had other operations and previous cardiac surgeries.

According to the operation method, the patients were divided into a mitral valve repair group (MVP) and a mitral valve replacement group (MVR). The comparative parameters included: population description, preoperative transthoracic echocardiography (TTE), operative and perioperative data, and TTE during follow-up. Adverse events related or possibly related to mitral valve operation were compared in the two groups. Heart failure was defined as death or hospitalization again for heart failure, or ejection fraction $\leq 45 \%$. The end events included death and reoperation because of the mitral valve.

All patients signed informed consent before surgery. The study design was approved by the Ethics Review Committee of Beijing Anzhen Hospital, an affiliate of Capital Medical University, Beijing, China.

\section{Surgical procedures}

Before the operation, all patients with rheumatic mitral valve stenosis in our center were evaluated by TTE according to Wilkins score. The pathological changes were further re-evaluated in the valve, commissure, and subvalvular apparatus by the surgeon during the operation. Whether to perform mitral valve repair or not was decided according to an intraoperative re-evaluation. Mitral valve replacement was considered only when the pathological changes were serious and not suitable for repair. The main repair method was commissurotomy, most of which were combined with leaflet slicing and ring annuloplasty. Some were combined with decalcification, artificial chordate transfer, chordal cutting, or papillary muscle dissection, if necessary (12). Transesophageal echocardiography was used to evaluate the effect of mitral valve repair before cardiopulmonary resuscitation. For patients undergoing mitral valve replacement, mechanical valves (mec-valves) or biological valves (bio-valves) were selected according to age and patients' wishes (6-8). All or part of the posterior valve and the subvalvular apparatus were preserved if possible.

\section{Follow-up $(14,15)$}

Excluding the perioperative deaths and perioperative reoperation, 902 patients entered follow-up. Follow-up data were obtained until January 2018, mainly through our follow-up website. This website was a new two-way interactive telemedicine follow-up system designed for discharged patients. It was established by our center in collaboration with a professional software company. It was constructed in 2013 and updated in 2018. An article in Chinese was dedicated to the introduction of the website (14). The main functions of the website are popular science education, data storage, and serving reminders. Patients may sign up and upload medical results voluntarily. Any doctor in our center who has seen patients is also granted access to upload data. Other follow-up methods included traditional direct contact with patients in outpatient clinics, or through telephone, text messages, e-mail, WeChat, or regular mail correspondence. Patients who cannot be contacted were regarded as censored.

\section{Propensity score matching}

Since valve replacement was considered only when the pathological changes were serious and unsuitable for repair, there might have been an inevitable bias in the selection between the two groups. A propensity score- 
matching study (hereafter referred to as PM) was therefore introduced for analysis. We picked out those MVP patients with pathological valves, and compared baseline indicators except those variables concerning valves [these included demographics, preoperative TTE, operation and perioperative variables (Table 1)] and the year of operation as matching reference factors. Corresponding to 902 follow-up patients, perioperative deaths and reoperation were excluded in the PM analysis. The other reason for the exclusion was that there was no significant difference in perioperative deaths and reoperation between the MVP and the MVR group, even after PM analysis in our pre-test. By comparing the data and drawing a survival curve before and after PM, a difference of prognosis between the two groups was observed and discussed.

\section{Left ventricular myocardial speckle-tracking strain analysis}

A SIEMENS SC2000 built-in VVI analysis program was used to detect the changes in longitudinal strain (LS) and circumferential strain (CS) of the left ventricle during follow-up, in 20 pairs of successfully matched patients with normal ejection fraction. Two-dimensional grayscale images were acquired from the parasternal short axis view at the mid-papillary level and the apical 4-chamber view $(16,17)$. We randomly selected 15 patients to be measured repeatedly and to evaluate the retest reliability of strain measurement.

\section{Statistical analysis}

Statistical analysis was completed using SPSS 22.0 software (IBM Corp., Armonk, NY, USA). Variables were expressed as means \pm SEM or frequencies. Univariate analysis was performed using a $t$-test, $\chi^{2}$, or Fisher exact test for two groups, and one-way ANOVA or rank-sum test for three groups. The method of propensity score matching was used to reduce the impact of selection bias. Test-retest reliability analysis was used to evaluate the reproducibility in the measurement of strain. The Kaplan-Meier survival analysis was designed to assess differences in MVP and MVR prognosis in patients for survival and freedom from adverse events, and with right censorings due to loss of followups. Throughout the paper, a $\mathrm{P}$ value $<0.05$ is considered statistically significant.

\section{Results}

\section{Population description}

A total of 921 cases were ultimately collected. There were 237 males and 684 females in this study (1/2.89). The mean age was 54.06 years, ranging from 23 to 82 years. In total, 349 cases $(349 / 921,37.9 \%)$ had mitral valve regurgitation moderate or above $(6,18)$. From 2011 to 2017 , the proportion of rheumatic mitral valve repair increased from $6.0 \%(7 / 116)$ in 2011 to $53.4 \%$ (70/131) in 2017.

The follow-up period was 3 months to 7.5 years, with a mean of 34.2 months. There were 37 patients lost to followup. These were patients with surgery performed before 2014, and we can neither reach them through landline telephone numbers nor their home addresses (provided in the patient-hospital forms). The follow-up rate was $96.0 \%$. Thirty-two patients died, all of whom were from the MVR group. The overall survival rate was $96.5 \%$. Ten cases were in reoperation because of the mitral valve. Among these, 2 cases were from the MVP group and 8 cases were from the MVR group. The overall reoperation rate was $1.1 \%$.

\section{Variable comparisons before and after PM}

\section{Comparisons during hospitalization}

Of the 921 patients, 221 were in the MVP group, and 700 were in the MVR group (including 192 bio-valves and 508 mec-valves). There was no significant difference between the two groups in mortality and reoperation rate. After PM, a total of 216 cases were matched. There were 108 cases in each group (for the MVR group, 37 cases of the biological valve and 71 cases of the mechanical valve). There was no significant difference between the two groups except for the left atrial dimension $(\mathrm{P}<0.05)$. Moreover, the gap of the left atrial dimension between the MVP and MVR groups was significantly reduced $(50.56 \pm 9.80,54.20 \pm 13.01)$ after PM.

\section{Comparisons during follow-up}

A total of 902 cases were included in the PM analysis. Before PM, the mean of the follow-up period was 19.8 months (3 months to 6.3 years) in the MVP group and 39.2 months (3 months to 7.5 years) in the MVR group. After PM, the follow-up period was the same in the MVP ( 3 months to 6.3 years, at a mean of 22.3 months) and MVR group ( 3 months to 7.1 years, at a mean of 23.0 months). The incidence of adverse events was significantly higher in 
Table 1 The baseline demographics and clinical variables in two groups pre- vs. post- propensity-score matching study

\begin{tabular}{|c|c|c|c|c|c|c|}
\hline Variables & \multicolumn{3}{|c|}{ Pre-PM $(n=921)$} & \multicolumn{3}{|c|}{ Post-PM (n=216) } \\
\hline \multicolumn{7}{|l|}{ Demographics } \\
\hline Age, years & $50.05 \pm 10.96$ & $55.47 \pm 10.26$ & 0.000 & $52.40 \pm 10.67$ & $54.10 \pm 9.98$ & 0.227 \\
\hline Gender & & & 0.048 & & & 0.362 \\
\hline Female & 174 & 510 & & 87 & 90 & \\
\hline Weight, kg & $62.52 \pm 10.22$ & $61.35 \pm 10.35$ & 0.142 & $62.09 \pm 10.11$ & $62.89 \pm 11.29$ & 0.585 \\
\hline Height, $\mathrm{cm}$ & $161.82 \pm 7.55$ & $161.22 \pm 7.48$ & 0.296 & $161.55 \pm 7.56$ & $160.86 \pm 6.89$ & 0.487 \\
\hline Creatinine, $\mu \mathrm{mol} / \mathrm{L}$ & $67.20 \pm 18.13$ & $76.89 \pm 56.71$ & 0.013 & $69.76 \pm 19.54$ & $71.56 \pm 16.65$ & 0.467 \\
\hline LVEDD, mm & $47.45 \pm 5.76$ & $47.43 \pm 5.94$ & 0.964 & $46.70 \pm 5.14$ & $47.18 \pm 5.18$ & 0.496 \\
\hline LVESD, mm & $31.76 \pm 5.07$ & $31.74 \pm 5.45$ & 0.973 & $31.05 \pm 4.60$ & $31.23 \pm 5.05$ & 0.778 \\
\hline $\mathrm{EF}, \%$ & $60.96 \pm 6.69$ & $60.72 \pm 7.39$ & 0.665 & $61.38 \pm 7.41$ & $61.19 \pm 7.07$ & 0.851 \\
\hline Mitral valve area, $\mathrm{cm}^{2}$ & $1.11 \pm 0.29$ & $0.98 \pm 0.26$ & 0.000 & $1.05 \pm 0.27$ & $1.08 \pm 0.24$ & 0.475 \\
\hline $\mathrm{EVmax}, \mathrm{cm} / \mathrm{s}$ & $197.43 \pm 52.11$ & $205.73 \pm 47.79$ & 0.032 & $194.92 \pm 65.25$ & $191.93 \pm 56.82$ & 0.720 \\
\hline Left atrial thrombi & 23 & 139 & 0.001 & 16 & 17 & 0.850 \\
\hline MR & & & 0.684 & & & 0.432 \\
\hline Non or mild & 140 & 432 & & 73 & 64 & \\
\hline AVR & 29 & 195 & 0.000 & 18 & 19 & 0.500 \\
\hline TVP & 199 & 628 & 0.501 & 94 & 100 & 0.130 \\
\hline $\mathrm{RF}$ & 145 & 549 & 0.000 & 74 & 76 & 0.441 \\
\hline Intubation, hour & $17.15 \pm 7.41$ & $18.66 \pm 12.11$ & 0.079 & $17.59 \pm 6.89$ & $18.27 \pm 14.80$ & 0.665 \\
\hline ICU time, hour & $23.10 \pm 13.16$ & $27.80 \pm 26.02$ & 0.010 & $24.35 \pm 15.17$ & $26.12 \pm 27.43$ & 0.558 \\
\hline IABP & 0 & 15 & 0.016 & 0 & 3 & 0.123 \\
\hline ECMO & 1 & 13 & 0.114 & 1 & 3 & 0.311 \\
\hline CRRT & 0 & 8 & 0.110 & 0 & 2 & 0.249 \\
\hline
\end{tabular}

Table 1 (continued) 
Table 1 (continued)

\begin{tabular}{|c|c|c|c|c|c|c|}
\hline Variables & \multicolumn{3}{|c|}{ Pre-PM (n=921) } & \multicolumn{3}{|c|}{ Post-PM (n=216) } \\
\hline \multicolumn{7}{|l|}{ Postoperative TTE } \\
\hline LVEDD, mm & $44.19 \pm 4.65$ & $45.04 \pm 5.10$ & 0.034 & $43.89 \pm 4.37$ & $44.75 \pm 4.85$ & 0.172 \\
\hline $\mathrm{EF}, \%$ & $61.68 \pm 6.57$ & $59.62 \pm 8.04$ & 0.000 & $62.24 \pm 7.07$ & $60.22 \pm 7.42$ & 0.053 \\
\hline EVmax, $\mathrm{cm} / \mathrm{s}$ & & $\begin{array}{c}\text { Bio-valves } \\
167.68 \pm 33.93\end{array}$ & 0.000 & & $\begin{array}{c}\text { Bio-valves } \\
170.85 \pm 34.75\end{array}$ & 0.058 \\
\hline MR & & & 0.000 & & & - \\
\hline Non or mild & 207 & $\begin{array}{c}698 \text { (5 mild peri-valve } \\
\text { leakage) }\end{array}$ & & 103 & - & \\
\hline Severe & 2 & - & & - & - & \\
\hline Death (cases) & 2 & $\begin{array}{c}8 \text { (Mec-valves } 5 \text {, Bio- } \\
\text { valves } 3)\end{array}$ & 0.556 & - & - & - \\
\hline Reoperation (cases) & 2 (severe reflux) & $\begin{array}{c}7 \text { (peri-valve leakage, } \\
\text { Mec-valves } 7, \text { Bio- } \\
\text { valves } 0 \text { ) }\end{array}$ & 0.629 & - & - & - \\
\hline
\end{tabular}

MVP, mitral valve repair group; MVR, mitral valve replacement group; PM, propensity score-matching study; TTE, transthoracic echocardiography; LAD, left atrial dimension; LVEDD, left ventricular end-diastolic diameter; LVESD, left ventricular end-systolic diameter; $\mathrm{EF}$, left ventricular ejection fraction; EVmax, transmitral E peak velocity; MR, mitral regurgitation; CPB, cardiopulmonary bypass; AVR, aortic valve replacement; TVP, tricuspid valve annuloplasty; RF, radiofrequency ablation; Bio-valves, biological valves; Mec-valves, mechanical valves; IABP, intra-aortic balloon pump; ECMO, extracorporeal membrane oxygenation; CRRT, continuous renal replacement therapy.

the MVR group $(\mathrm{P}<0.05)$ (Table 2).

The area of the mitral valve orifice was further compared between the MVP, bio-valve MVR, and mec-valve MVR group. Whether before or after PM, there was no significant difference of mitral valve area in the MVP and bio-valve MVR group, as to the mec-valve MVR group, the area of the prosthetic valve was higher, but the maximum flow velocity of the E-peak was not smaller than that in the MVP group. These suggest that the valve area of the MVP group was within an acceptable range.

As to regurgitation in the MVP group of 217 patients, 14 cases were in moderate or above levels. This included 1 case of severe reflux which had a New York Heart Association (NYHA) class III reoperation 1 year and 10 months after surgery. Five cases of moderate to severe reflux which had NYHA class II are currently and carefully being followed up. The other 8 patients of moderate reflux had no significant clinical symptoms and are currently in clinical followup. There was no increase in the risk of reoperation compared with the replacement group $(\mathrm{P}>0.05)$. Therefore, from the perspective of the valve, mitral valve repair was feasible.

\section{Kaplan-Meier survival analysis}

The Kaplan-Meier survival analysis showed that there was statistically significant $(\mathrm{P}<0.05)$ differences in mortality between MVP and MVR before PM, but no significant difference after PM. As to adverse events, the incidence was much higher in the MVR group than that in the MVP group after $\mathrm{PM}(\mathrm{P}<0.05)$ (Figures 1,2).

\section{Left ventricular myocardial speckle-tracking strain analysis}

Instead of following the standard procedure of the 
Table 2 Follow-up variables in two groups pre- $v s$. post-propensity score matching study

\begin{tabular}{|c|c|c|c|c|c|c|}
\hline Variables & \multicolumn{3}{|c|}{ Pre-PM (n=902) } & \multicolumn{3}{|c|}{ Post-PM (n=216) } \\
\hline \multicolumn{7}{|l|}{ Loss of follow-up } \\
\hline Cases (total, follow-up rate) & $1(217,99.5 \%)$ & $36(685,94.7 \%)$ & 0.000 & $1(108,99.1 \%)$ & $3(108,97.2 \%)$ & 0.098 \\
\hline Operation & & & - & & & - \\
\hline 2012 & $0(8,100.0 \%)$ & $12(132,90.9 \%)$ & & $0(5,100.0 \%)$ & $0(13,100.0 \%)$ & \\
\hline 2013 & $1(12,91.7 \%)$ & $8(130,93.8 \%)$ & & $1(7,85.7 \%)$ & $1(8,87.5 \%)$ & \\
\hline 2014 & $0(41,100.0 \%)$ & $2(68,97.1 \%)$ & & $0(21,100.0 \%)$ & $0(12,100.0 \%)$ & \\
\hline 2015 & $0(27,100.0 \%)$ & $0(108,100.0 \%)$ & & $0(13,100.0 \%)$ & $0(24,100.0 \%)$ & \\
\hline Cases & 12 & 81 & 0.002 & 2 & 8 & 0.041 \\
\hline \multicolumn{7}{|l|}{ Types } \\
\hline Heart failure & 1 & 27 & 0.010 & 0 & 4 & 0.040 \\
\hline Neurologic event & 0 & 19 & 0.013 & 0 & 1 & 0.325 \\
\hline Abnormal valve & $\begin{array}{l}8 \text { (Moderate to } \\
\text { severe reflux 6; } \\
\text { severe MS 2) }\end{array}$ & $\begin{array}{c}22 \text { (peri-valve leakage 16; } \\
\text { abnormal of artificial valve } \\
5 \text {; bio-valve damage } 1 \text { ) }\end{array}$ & 0.437 & $\begin{array}{l}2 \text { (moderate to } \\
\text { severe reflux 2) }\end{array}$ & $\begin{array}{l}3 \text { (peri-valve } \\
\text { leakage 3) }\end{array}$ & 0.620 \\
\hline $\begin{array}{l}\text { Atrial or auricular } \\
\text { thrombus }\end{array}$ & 2 & 6 & 0.948 & 0 & 0 & - \\
\hline \multicolumn{7}{|l|}{ Death } \\
\hline Cases & 0 & $\begin{array}{l}32 \text { (mec-valves } 21 \\
\text { bio-valves } 11)\end{array}$ & 0.000 & 0 & $\begin{array}{c}3 \text { (mec-valves } 1 ; \\
\text { bio-valves } 2 \text { ) }\end{array}$ & 0.385 \\
\hline \multicolumn{7}{|l|}{ Reason } \\
\hline Neurologic event & 0 & $\begin{array}{l}12 \text { (mec-valves } 8 ; \\
\text { bio-valves } 4 \text { ) }\end{array}$ & - & 0 & $\begin{array}{c}1 \text { (mec-valves } 1 ; \\
\text { bio-valves } 0 \text { ) }\end{array}$ & - \\
\hline Heart failure & 0 & 9 & - & 0 & 1 & - \\
\hline Multisystem infection & 0 & 3 & - & 0 & 1 & - \\
\hline Pulmonary embolism & 0 & 1 & - & 0 & 0 & - \\
\hline Splenic embolization & 0 & 1 & - & 0 & 0 & - \\
\hline Sudden death & 0 & 2 & - & 0 & 0 & - \\
\hline Noncardiac & 0 & 1 & - & 0 & 0 & - \\
\hline Unknown & 0 & 3 & - & 0 & 0 & - \\
\hline
\end{tabular}

Table 2 (continued) 
Table 2 (Continued)

\begin{tabular}{|c|c|c|c|c|c|c|}
\hline Variables & \multicolumn{3}{|c|}{ Pre-PM (n=902) } & \multicolumn{3}{|c|}{ Post-PM (n=216) } \\
\hline \multicolumn{7}{|l|}{ Reoperation } \\
\hline Cases & 2 & $\begin{array}{c}8 \text { (mec-valves } 8 ; \\
\text { bio-valves } 0 \text { ) }\end{array}$ & 0.514 & 1 & 0 & 0.316 \\
\hline Perivalvular leakage & 0 & 3 & - & 0 & 0 & - \\
\hline AFAV & 0 & 4 & - & 0 & 0 & - \\
\hline IE & 1 & 1 & - & 0 & 0 & - \\
\hline LVESD, mm & $29.91 \pm 4.23$ & $30.76 \pm 5.05$ & 0.067 & $30.17 \pm 3.99$ & $30.21 \pm 4.84$ & 0.954 \\
\hline$E F, \%$ & $61.90 \pm 5.64$ & $60.85 \pm 7.74$ & 0.108 & $61.33 \pm 5.61$ & $61.40 \pm 6.65$ & 0.942 \\
\hline \multirow[t]{2}{*}{ EVmax, cm/s } & $159.90 \pm 35.71$ & Mec-valves $171.57 \pm 33.63$ & 0.001 & $160.74 \pm 35.54$ & $\begin{array}{c}\text { Mec-valves } \\
173.92 \pm 36.11\end{array}$ & 0.040 \\
\hline & & Bio-valves $177.03 \pm 35.06$ & 0.000 & & $\begin{array}{c}\text { Bio-valves } \\
181.90 \pm 35.87\end{array}$ & 0.006 \\
\hline Valve area, $\mathrm{cm}^{2}$ & $2.26 \pm 0.42$ & Mec-valves $2.90 \pm 0.39$ & 0.000 & $2.23 \pm 0.32$ & $\begin{array}{c}\text { Mec-valves } \\
2.89 \pm 0.38\end{array}$ & 0.000 \\
\hline
\end{tabular}

MVP, mitral valve repair group; MVR, mitral valve replacement group; PM, propensity score-matching study; bio-valves, biological valves; mec-valves, mechanical valves; MR, mitral regurgitation; AFAV, abnormal function of artificial valve; IE, infective endocarditis; TTE, transthoracic echocardiography; LAD, left atrial dimension; LVEDD, left ventricular end-diastolic diameter; LVESD, left ventricular endsystolic diameter; EF, left ventricular ejection fraction; EVmax, transmitral E peak velocity.

SIEMENS SC2000 VVI analysis program, we added one additional step to reduce measurement errors: after outlining the endocardium border and clicking the "analysis" button, we returned to click the "contour" button again. This extra step was essential. We judged the internal and external membrane tracking with our naked eyes. If the tracking was satisfactory, we clicked the "analysis" button again, continuing with the subsequent analysis program. Otherwise, the images were considered failed, and further analysis was pursued. Test-retest coefficient analysis for the correlation coefficient of LS and CS were 0.936 and $0.917(\mathrm{P}<0.05)$ respectively, meaning retest reliability was the higher of the two. Left ventricular myocardial strain analysis showed that LS was significantly lower in the MVR group $(\mathrm{P}<0.05)$, and there was no significant difference in CS measure $(\mathrm{P}>0.05)$ (Table 3 and Figure 3$)$.

\section{Discussion}

In the limited reports on the repair of the rheumatic mitral valve, the majority of rheumatic mitral valve lesions were regurgitation $(10,19)$. Our data was different. There were only 349 cases in moderate (or more) mitral valve regurgitation, accounting for just $37.9 \%$ of the 921 cases. Also, unlike previous studies (10,19-21), our study had a predominantly female population (2.89:1 female $v s$. male 
A

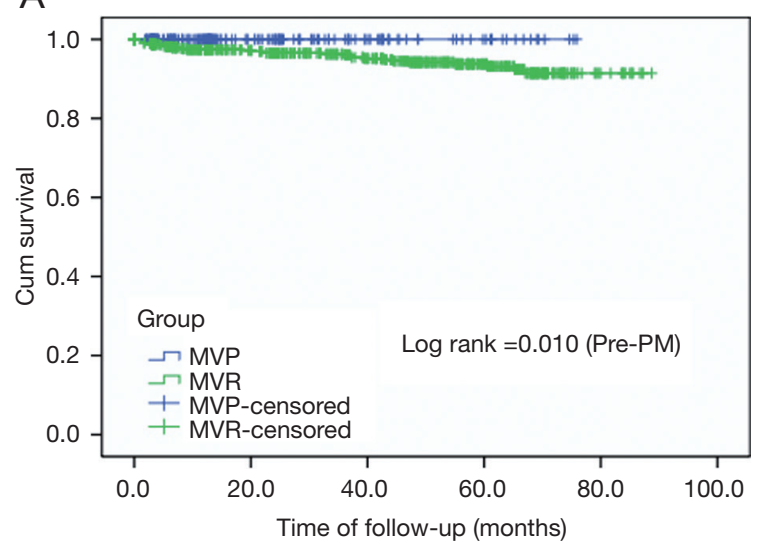

Number of survival

$\begin{array}{lllll}\text { MVP } & 217 & 80 & 37 & 15\end{array}$

$\begin{array}{lllll}\text { MVR } & 685 & 451 & 328 & 164\end{array}$
B

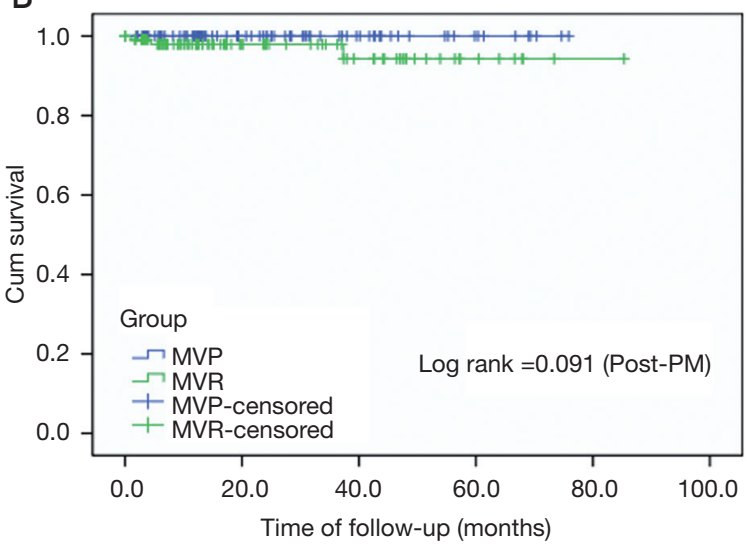

Number of survival

$\begin{array}{llllll}\text { MVP } & 108 & 45 & 22 & 8 & \\ \text { MVR } & 108 & 41 & 23 & 7 & 1\end{array}$

Figure 1 Kaplan-Meier survival analysis for survival of the two groups pre- vs. post-propensity score matching. MVP, mitral valve repair group; MVR, mitral valve replacement group; PM, propensity score-matching study.

A

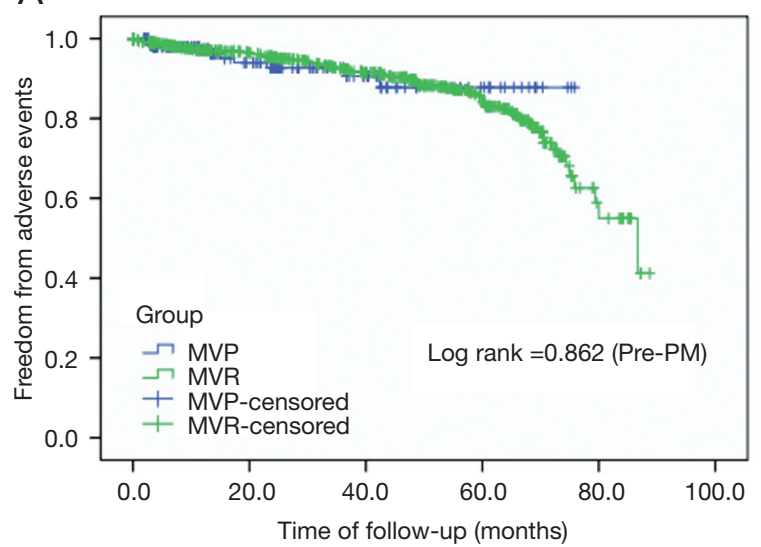

Number of freedom from adverse events

$\begin{array}{llll}\text { MVP } & 217 & 80 & 37\end{array}$

$\begin{array}{llllrr}\text { MVR } & 685 & 451 & 328 & 164 & 15\end{array}$
B

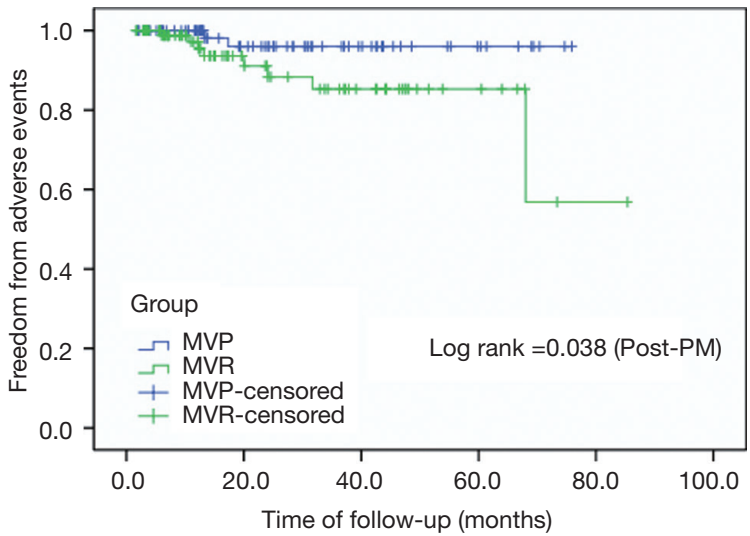

Number of freedom from adverse events

$\begin{array}{lllll}\text { MVP } & 108 & 44 & 22 & 8\end{array}$

$\begin{array}{llllll}\text { MVR } & 108 & 40 & 23 & 7 & 1\end{array}$

Figure 2 Kaplan-Meier survival analysis for freedom from adverse events of the two groups pre- vs. post-propensity score matching. MVP, mitral valve repair group; MVR, mitral valve replacement group; PM, propensity score-matching study.

ratio), with a higher average age (54.06 years old), and a higher incidence of atrial fibrillation $(694 / 921,75.4 \%)$; in general, it was more severe in rheumatic mitral lesions.

As an imaging change, Wilkins Score was still the most critical preoperative assessment method for rheumatic valvular damage (22). The preoperative ultrasound evaluation was not wholly parallel to the actual pathological changes under direct vision during the operation; sometimes, the difference was even more substantial $(12,13)$. Luo et al. suggested evaluating the valve preoperatively by echocardiography and further confirming it under direct vision during the operation. Such subdivision of severe rheumatic mitral stenosis enabled us to repair as much as possible.

Only patients with severe pathological changes were considered for valve replacement. Therefore, the MVR 
Table 3 Left ventricular myocardial speckle-tracking strain analysis

\begin{tabular}{lccc}
\hline Strain & MVP & MVR & P value \\
\hline Longitudinal strain (\%) & $-19.41 \pm 2.18$ & $-17.79 \pm 2.64$ & 0.031 \\
Circumferential & $-25.91 \pm 4.20$ & $-26.08 \pm 6.13$ & 0.918 \\
strain (\%) & & & \\
\hline
\end{tabular}

MVP, mitral valve repair group; MVR, mitral valve replacement group.

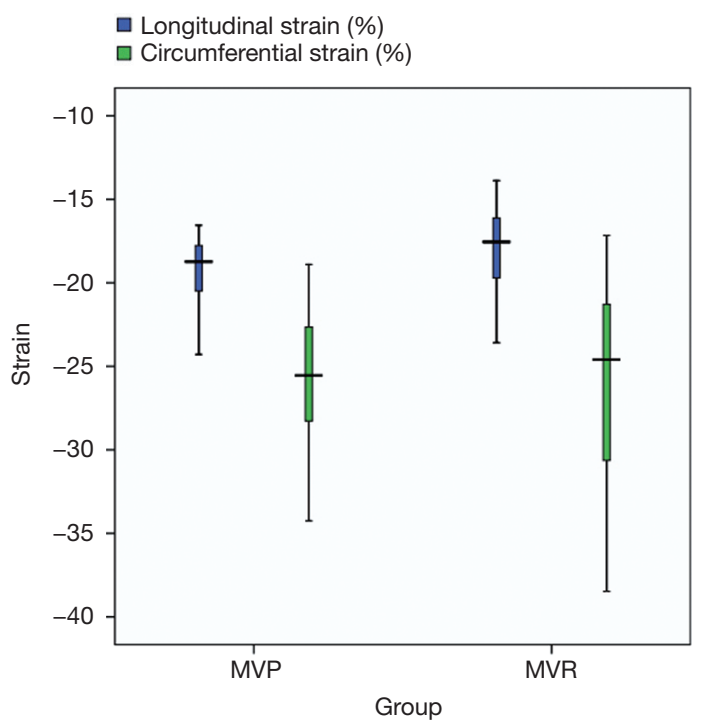

Figure 3 Left ventricular myocardial speckle-tracking strain analysis.

group was selected to be more likely to have severe valve lesions. This introduced an inevitable selection bias between the two groups. However, the critical issue was that the repair rate was extremely low in these patients under normal circumstances. We picked out the MVP patients through the valve pathological analysis, and compared baseline indicators except for the valve. In this way, we wanted to show that selecting suitable patients for mitral valve repair is feasible even for patients with severe rheumatic mitral stenosis. A statistical method of PM was introduced in order to eliminate the baseline disparities between the MVP and MVR groups as much as possible. There was no significant difference in any of the parameters except left atrial dimension after PM. In principle, with the increase of mitral stenosis, the load of the left atrium should have increased, and the inner diameter of the left atrium should have increased as well $(13,23)$. However, the difference between the two groups was significantly reduced $(50.56 \pm 9.80,54.20 \pm 13.01)$ after PM. According to our clinical experience, we considered this difference to be within an acceptable range. Based on the above analysis, we believe that the matching successfully eliminated disparities between the two groups to a maximum extent.

The Kaplan-Meier survival curve analysis showed that the two different kinds of operations had no significant difference as far as medium-term mortality was concerned after PM. For further analysis of the cause of death, we found that of the 32 cases of death, 12 cases died with neurological events. It was unexpected that the bio-valve MVR group accounted for a considerable proportion, and the mortality rate $(4 / 189,2.1 \%)$ even exceeded the mecvalve replacement group (8/496, 1.6\%). Among the 4 biovalve MVR patients, 3 had recurrent atrial fibrillation but did not take warfarin. According to the 2014 American Heart Association/American College of Cardiology (AHA/ ACC) guideline for valvular heart disease, patients with secondary atrial fibrillation after bio-prosthetic mitral valve replacement were advised to continue taking warfarin (6). Thus, it was essential to remind patients for postoperative standard follow-up and continue anti-coagulation after atrial fibrillation recurrence.

Similar to the report of Kim et al. (20), the incidence of adverse events in follow-up were higher in the MVR patients in our study. We unexpectedly found a significant incidence of heart failure in the MVR group. The following might be possible reasons: (I) rheumatism damage was more severe in the MVR group when compared to the MVP group. We saw that, even after PM, the size of the left atrium in the MVR group was still more substantial than that in the MVP group, suggesting that the lesion of the mitral valve lesion was more severe and thus led to more prolonged and more severe myocardial damage in MVR. (II) The replacement surgery might have changed the normal physiological structure of the heart. Under normal conditions, the pull of the sub-valve apparatus would have made the heart maintain the original tension and shape. Even with all or part of the posterior valve and subvalvular apparatus possibly preserved, the replacement surgery might have inevitably changed the normal physiological structure of the heart. Did this reduce further damage to the cardiac function? To answer this question, we selected a group of patients who were successfully matched with clear ultrasound images. Using the ultrasonic speckletracking technique, we quantitatively analyzed the left ventricular myocardial strain, trying to provide clues for our 
speculations through this small sample.

At present, it is believed that the echocardiogram speckle-tracking technique can better predict subclinical events than conventional parameters (17). In this study, we only selected the regional LS of the apical view of the fourchamber level and the regional CS of the short axial view of the mid-papillary level. The reasons for this were as follows: (I) these two levels were relatively easy to acquire clear images, and they were routinely retained in our center; (II) the papillary muscle traction was lost entirely or partially in the MVR group, which unavoidably changed the typical physiological structure of the heart. The regional myocardial strain may be more sensitive than the global strain (24); (III) according to the theory of myocardial band (25-27), the papillary muscles emerged from the descending segment of the apical loop. Together with the anterolateral left ventricle and the ventricular septum, these three parts defined the bulk of the myocardium descending, the complete contraction and ejection during the systolic period. Therefore, the short axial view of the mid-papillary level and apical view of four-chamber level were the two sections that could directly receive the pull of the papillary muscle. In this cohort, there was no significant difference in CS between the MVP and the MVR groups, but LS was significantly lower in the MVR. This result was similar to previous reports of severe mitral regurgitation and heart failure $(16,28)$. That is, global LS indicated a decline of cardiac function more sensitively and during its early onsets before the change of routine detection. Given the above results, future prospective, large sample, randomized studies and follow-up studies are warranted.

Next, we discuss possible limitations of our study and put our conclusions into perspective. First, as a retrospective study, although we applied the method of PM, we were limited by data availability and could not fully include all the influencing factors. We may not have eliminated all intergroup disparities. Second, the quantitative analysis of left ventricular myocardial strain tracing was only based on a small sample; it was not enough to explain the essence of myocardial contraction. Further studies of a prospective nature, with a large, randomized sample and subsequent follow-up are necessary.

\section{Conclusions}

Selecting suitable patients for mitral valve repair is feasible even for patients with severe rheumatic mitral stenosis. In our study, compared with the prosthetic valve replacement in these patients, valve repair still significantly reduced the valve-related complications rates and improved the quality of life during the follow-up.

\section{Acknowledgments}

None.

\section{Footnote}

Conflicts of Interest: The authors have no conflicts of interest to declare.

Ethical Statement: The authors are accountable for all aspects of the work in ensuring that questions related to the accuracy or integrity of any part of the work are appropriately investigated and resolved. The study design was approved by the Ethics Review Committee of Beijing Anzhen Hospital (No. 2019016x).

\section{References}

1. Remenyi B, ElGuindy A, Smith SC, et al. Valvular aspects of rheumatic heart disease. Lancet 2016;387:1335-46.

2. Chen WW, Gao RL, Liu LS, et al. Chinese cardiovascular disease report 2017 profile. Chinese Circulation Journal 2018;33:1-8.

3. Harb SC, Griffin BP. Mitral valve disease: a comprehensive review. Curr Cardiol Rep 2017;19:73.

4. Thomas MP, Badhwar V. A three-step technique for repair of rheumatic disease of the mitral valve. Cardiol Young 2014;24:1104-7.

5. Horstkotte D, Niehues R, Strauer BE. Pathomorphological aspects, aetiology and natural history of acquired mitral valve stenosis. Eur Heart J 1991;12 Suppl B:55-60.

6. Nishimura RA, Otto CM, Bonow RO, et al. 2014 AHA/ ACC guideline for the management of patients with valvular heart disease: a report of the American College of Cardiology/American Heart Association Task Force on Practice Guidelines. J Thorac Cardiovasc Surg 2014;148:e1-132.

7. DiBardino DJ, ElBardissi AW, McClure RS, et al. Four decades of experience with mitral valve repair: analysis of differential indications, technical evolution, and long-term outcome. J Thorac Cardiovasc Surg 2010;139:76-83.

8. Vassileva CM, Mishkel G, McNeely C, et al. Long-term survival of patients undergoing mitral valve repair and replacement:a longitudinal analysis of Medicare fee-for- 
service beneficiaries. Circulation 2013;127:1870-6.

9. Saurav A, Alla VM, Kaushik M, et al. Outcomes of mitral valve repair compared with replacement in patients undergoing concomitant aortic valve surgery: a metaanalysis of observational studies. Eur J Cardiothorac Surg 2015;48:347-53.

10. Bakir I, Onan B, Onan IS, et al. Is Rheumatic Mitral Valve Repair Still a Feasible Alternative? Tex Heart Inst J 2013;40:163-9.

11. Hirota M, Isomura T, Katsumata C, et al. Mid-term results of mitral valve palsty in patients with mitral sclerotic lesion. J Cardiothorac Surg 2016;11:81.

12. Tiange $\mathrm{L}, \mathrm{Xu}$ M. Repair Strategies Based on Pathological Characteristics of the Rheumatic Mitral Valve in Chinese Patients. Heart Lung Circ 2018 27:856-63.

13. Luo T, Han J, Meng X. Features of rheumatic mitral valves and a grading system to identify suitable repair cases in China. J Thorac Dis 2017;9:3138-47.

14. Jiao YQ, Wang JG, Zhang HB, et al. Establishment and Improvement of Cardiac Post-Operation Follow-up Database. Chinese Hospital Management 2015;35:53-5.

15. Akins CW, Miller DC, Turina MI, et al. Guidelines for reporting mortality and morbidity after cardiac valve interventions. J Thorac Cardiovasc Surg 2008;135:732-8.

16. Yip GW, Zhang Q, Xie JM, et al. Resting global and regional left ventricular contractility in patients with heart failure and normal ejection fraction: insights from speckletracking echocardiography. Heart 2011;97:287-94.

17. Kim HM, Cho GY, Hwang IC, et al. Myocardial Strain in Prediction of Outcomes After Surgery for Severe Mitral Regurgitation. JACC Cardiovasc Imaging 2018;11:1235-44.

18. Lancellotti P, Tribouilloy C, Hagendorff A, et al. Recommendations for the echocardiographic assessment of native valvular regurgitation: an executive summary from the European Association of Cardiovascular Imaging. Eur Heart J Cardiovasc Imaging 2013;14:611-44.

Cite this article as: Jiao Y, Luo T, Zhang H, Han J, Li Y, Jia Y, Zheng S, Meng X. Repair versus replacement of mitral valves in cases of severe rheumatic mitral stenosis: mid-term clinical outcomes. J Thorac Dis 2019;11(9):3951-3961. doi: 10.21037/ jtd.2019.08.101
19. Cardoso B, Loureiro P, Gomes I, et al. Mitral Valve Surgery for Rheumatic Lesions in Young Patients. World J Pediatr Congenit Heart Surg 2016;7:321-8.

20. Kim WK, Kim HJ, Kim JB, et al. Clinical outcomes in 1731 patients undergoing mitral valve surgery for rheumatic valve disease. Heart 2018;104:841-8.

21. Chotivatanapong T, Lerdsomboon P, Sungkahapong V. Rheumatic mitral valve repair: experience of 221 cases from Central Chest Institute of Thailand. J Med Assoc Thai 2012;95 Suppl 8:S51-7.

22. Wilkins GT, Weyman AE, Abascal VM, et al. Percutaneous balloon dilatation of the mitral valve: an analysis of echocardiographic variables related to outcome and the mechanism of dilatation. Br Heart J 1988;60:299-308.

23. Bakir I, Casselman FP, Brugada P, et al. Current strategies in the surgical treatment of atrial fibrillation: review of the literature and Onze Lieve Vrouw Clinic's strategy. Ann Thorac Surg 2007;83:331-40.

24. Carstensen HG, Larsen LH, Hassager C, et al. Association of ischemic heart disease to global and regional longitudinal strain in asymptomatic aortic stenosis. Int J Cardiovasc Imaging 2015;31:485-95.

25. Buckberg GD, Clemente C, Cox JL, et al. The structure and function of the helical heart and its buttress wrapping. IV. Concepts of dynamic function from the normal macroscopic helical structure. Semin Thorac Cardiovasc Surg 2001;13:342-57.

26. GD B. Basic science review: the helix and the heart. J Thorac Cardiovasc Surg 2002;124:863-83.

27. Torrent-Guasp F, Kocica MJ, Corno AF, et al. Towards new understanding of the heart structure and function. Eur J Cardiothorac Surg 2005;27:191-201.

28. Cho EJ, Park SJ, Yun HR, et al. Predicting Left Ventricular Dysfunction after Surgery in Patients with Chronic Mitral Regurgitation: Assessment of Myocardial Deformation by 2-Dimensional Multilayer Speckle Tracking Echocardiography. Korean Circ J 2016;46:213-21. 